\title{
Moderate sensory balance training leads to improvements in elderly
}

\author{
Lara A. Thompson
}

*Correspondence: Ithomps@alum.mit.edu

Associate Professor Mechanical Engineering, Biomedical Engineering Program Director, University of the District of Columbia, Washington, DC, 20008 USA.

\begin{abstract}
Background: With increases in average life expectancy (i.e., 43 million Americans over 65 years old in 2012 and 72 million projected in 2030), the importance of investigating and establishing accessible training methodologies towards good balance and preventing falls has significant societal relevance. It is well known that information from somatosensory, visual and vestibular systems integrate to yield a postural response and that these systems may degrade with age. It was hypothesized that modest and accessible training exercises targeting sensory inputs and base-of-support (BOS) improves balance and balance confidence in mature participants $(60-80$ years old).

Methods: Sixteen participants were assessed pre/post 6 weeks of training, 2 sessions/week involving moderate (meaning low-intensity) walking (wide and tandem) and standing (single-leg, tandem and double-leg) while we varied visual and somatosensory inputs (i.e., eyes-open/closed and hard surface \& stiff/compliant foam surfaces). Baseline and final assessments included standard measures (Balance Error Scoring System (BESS) and Activities-specific Balance Confidence (ABC)), as well as forceplate-derived center-of-pressure (COP) displacement and velocity parameters.

$\underline{\text { Results: }}$ From relatively simple, targeted exercises, we observed that BESS scores improved from broadly normal/poor (baseline) to superior (final) performance and improvements (decreases) in both COP parameters.

Conclusions: The results of the training were significant in that by doing sensory/BOS exercises, the participants were able to improve postural control and balance; this implies decreased risk of losing stability and falls. Further, these exercises are accessible and simple enough to be translated to one's home.

Keywords: Geriatric, rehabilitation, falls, posture, balance, elderly, aging, training, sensory systems
\end{abstract}

\section{Introduction}

Training to improve balance and reduce falls in mature individuals holds significant societal relevance. For American individuals over 65 years of age, falls are the leading cause of injury-related death [1-4]. Critical to reducing fall-risk in the mature, aging population are user-friendly,low-impact training methodologies for balance maintenance, improvement, and confidence (e.g., [5-9]).

It is well-known that the control of one's posture is maintained by sensorimotor integration of the visual, vestibular, and somatosensory system inputs [10]. Further, there is general agreement that decreased postural ability in mature \& elderly individuals is linked to/could reflect pathologies associated with one or more of these sensory system components, as well as age-related changes and deterioration of motor and higher-level adaptive mechanisms [5,11-14]. The improvement of elderly individual's balance via training is of relevant societal importance (e.g., [5-9]). However, how elderly individual's sensorimotor integration (to impact one's balance) is affected due to readily-accessible balance training methodologies, namely sensory-type training, requires more rigorous study.

The purpose of this study was to investigate if modest and 
accessible training exercises targeting sensory inputs and base-of-support (BOS) could improve balance (as observed by the Balance Error Scoring System (BESS) assessment and center-of-pressure COP) and balance confidence (as observed by the Activities Specific Balance Confidence (ABC) scale in mature participants (60-80 years old).

\section{Balance Error Scoring System (BESS)}

Due to its low-impact and accessibility, moderate-level (meaning physically low-intensity with low-risk of injury) sensory and base-of-support (BOS) training should be examined; aside from sensory system inputs, BOS also impacts one's ability to maintain balance [10]. Perhaps the most straight forward, accessible, and widely-used methodology to assessone's ability to balance, while modifying BOS and support surface cues, is the Balance Error Scoring System (BESS). Some advantages to the BESS are that it is standardized (commonly used), rapid, inexpensive \& easy to perform (minimal (no) equipment needed), and helpful for quick monitoring and tracking. Here, the BESS assessment was used for two reasons:

1) it is a standardly-used and accessible measure for balance from which comparisons between (other) studies could be based; 2 ) it allowed for variation of somatosensory cues (i.e., hard vs. foam support surface) as well as variation of base of support (stance widths of wide, tandem and single-leg) thereby allowing for measures of differences in balance (in terms of BESS errors) with increases in task difficulty.

In regards to the BESS, there were three hypotheses: 1 ) that a common assessment (BESS) can be used to characterize changes in balance as a function of task-difficulty pre- and post- several weeks of training; 2 ) that by using simple sensory training and BOS exercises over several weeks, participants would be able to improve broadly normal or below average performance at onset (baseline) towards superior or above average performance at conclusion (final); and 3) that as BESS task-difficulty increased, the number of errors would be reduced in the trained participants relative to their baseline measures; this indicates improved balance, but could also perhaps indicate improvements in how the sensory systems were integrating information post-training.

\section{Center-of-Pressure (COP)}

Another standard method to quantify balance is measuring the center-of-pressure (COP) time series. Extracting parameters from the COP series leads to well-defined measures of balance performance [15-22]. Previously, Prieto et al. [15] was the first to utilize displacement, velocity, and frequency measures extracted from participants' COP time series to quantify differences in postural steadiness between young adults and healthy elderly adults with eyes-open/closed conditions. Results indicated that multiple measures may be necessary to characterize differences between groups. However, setbacks included not assessing roles of BOS nor foam (only vision was altered for quiet standing on a hard surface) using a forceplate.
Most importantly, the effects of sensory training were not examined (i.e., only a baseline measure was obtained, not an evaluation of the effects post repeated training activities).

In our study, two static balance tests (BESS Assessment and quiet standing on a forceplate walkway) were utilized. Static tests are relevant to functional stability in daily life for two reasons: 1) a sizable proportion (nearly half) of falls occur during nearstatic movements and activities and 2) static test results may provide information that is relevant to the many falls that occur during gait [23].

It was hypothesized that simple exercises over several weeks of moderate sensory training would be able to improve (decrease) COP displacement and velocity in both medio-lateral (ML) \& anterior-posterior (AP) directions in mature participants which indicates better postural stability and control, respectively.

\section{Balance confidence in elderly adults}

Although balance control changes in older adults may be attributed to underlying physiological factors linked to one's capabilities, there are also psychological factors, such as fear of falling and low balance confidence \& efficacy, which affect performance. For example, Carpenter et al., [22] hypothesized that as the balance challenge increased (e.g., standing at height), there would be increases in anxiety, blood pressure, as well as decreased in self-efficacy in older adults. Carpenter et al. [22] noted that older adults used stiffening strategy (similar to young adults) to cope with increases in anxiety and lowered confidence while standing on an elevated surface. The basis for their research was that fear of falling in older adults can lead to altered behavior (e.g., restricted activity, decreased independence, and avoidance of scenarios wherein one's balance may be challenged). Fear of falling and low balance confidence may contribute to (balance) scenario avoidance changes in the elderly which limits their activities or the types of activities they would pursue. Here, to measure balance confidence, the standard Activities-specific Balance Confidence (ABC) scale was utilized. It was hypothesized that through simple, targeted sensory training balance confidence of mature participants could be improved.

\section{Methods}

All experiments for this study were conducted within the Center for Biomechanical \& Rehabilitation Engineering (CBRE) at the University of the District of Columbia (UDC) and the protocol was approved by the UDC Institutional Review Board (979744-1). Participants were recruited from the UDC Institute of Gerontology, by word of mouth, and via posted study flyers. Informed consent was obtained prior to participants taking part in the study. All study participants needed to be between 60 to 80 years of age and considered themselves healthy (i.e., free from disease and of good physical, mental, and social well-being). For example, participants should have not previously suffered a stroke had Parkinson's Disease nor 
Alzheimer's Disease. Further, to take part in the study, all participants had to be able to ambulate at least $10 \mathrm{~m}$ without assistance, without use of a cane or walker, and were not any medications that would cause vertigo or imbalance. Prior to proceeding with the study, all participants' cognitive abilities were screened via the Mini-Mental State Examination (MMSE). The MMSE is a 30-point questionnaire used extensively in clinical and research settings to measure cognitive impairment and to screen for dementia. All study participants obtained MMSE scores of 30 (perfect) indicating no cognitive impairment. Training, as well as pre- and post assessments, were performed on 16 participants: 12 females (69.8 years old $+/-6.3$ years) and 4 male participants ( 64.7 years old $+/-3.5$ years old).

\section{Training}

Participants completed a 6-week exercise routine that consisted of two, 30 minute sessions/week. During the training sessions, the subjects donned a harness attached to a support system to prevent them from falling. Further, during the sessions, the participants worked with the principal investigator and two to three research technicians each session which also served as spotters during all exercises. The training is outlined in (Table 1).

\section{Assessments and Measures}

Because visual, somatosensory and vestibular systems are used for postural control, and further, BOS impacts one's balance, for our training and test battery we varied visual cues, somatosensory cues, and also stance width to vary task-difficulty level (i.e., fewer cues yielded greater task-difficulty).

Each participant was assessed prior to training taking place and therefore served as their own control. In other words, baseline (or control data) was taken for each and every individual at (baseline, or pre) week 1, prior to training and each participant was assessed again at week 6 at the conclusion of their training (final, or post). In this way, each participant (i.e., data collected at week 1 in the initial session, prior to training) served as their own control.

\section{Balance Error Scoring System (BESS) Assessment}

The BESS assessment utilizing double-leg, single-leg, and tandem stances as the participant stands on either hard or foam support surfaces, all without visual input (eyes-closed). In order of increasing difficulty were: 1) hard-surface/double-leg (easiest), 2) foam-surface/double-leg, 3) hard-surface/tandem, 4) foam-surface/tandem, 5) hard-surface/single-leg, and 6) foam- surface/single-leg (most difficult).

The number of deviations from upright are counted as 'errors' for six, 20 second trials per condition. A higher score could be interpreted as lesser ability to balance; conversely, a lower score (i.e., fewer deviations) could be interpreted as a better ability to balance. Some examples of errors to be counted were

Table 1. Training Plan Outline.

\begin{tabular}{|c|c|c|}
\hline $\begin{array}{l}\text { Training I. Walking Exercises } \\
\text { first } 4 \text { sessions }\end{array}$ & $\begin{array}{l}\text { Training II. Foam Exercises } \\
\text { intermediate } 4 \text { sessions }\end{array}$ & $\begin{array}{c}\text { Training III. Walking over } \\
\text { obstacles and more foam } \\
\text { Exercises } \\
\text { final } 4 \text { sessions }\end{array}$ \\
\hline \multirow{2}{*}{$\begin{array}{l}\text { Walking straight ahead }(3 \mathrm{~m}) \text {, } \\
\text { side-stepping to the right }(1.5 \mathrm{~m}) \text {, } \\
\text { walking backwards }(3 \mathrm{~m}) \text {, side- } \\
\text { stepping to the left }(1.5 \mathrm{~m}) \text { and } \\
\text { repeating ten times }\end{array}$} & \multirow{2}{*}{$\begin{array}{l}\text { Ankle raises on the foam, three } \\
\text { sets of ten (eyes-open/closed) }\end{array}$} & $\begin{array}{l}\text { Walking eyes-closed, forward } \\
(3 \mathrm{~m}) \text { and back }(3 \mathrm{~m}) \text {, on harder } \\
\text { foam }\end{array}$ \\
\hline & & $\begin{array}{l}\text { Walking eyes-closed on harder } \\
\text { foam and over compliant foam } \\
\text { obstacle }\end{array}$ \\
\hline $\begin{array}{l}\text { Walking straight ahead }(3 \mathrm{~m}) \\
\text { (tandem foot placement), side- } \\
\text { stepping to the right }(1.5 \mathrm{~m}) \text {, } \\
\text { walking backwards }(3 \mathrm{~m})(\text { tandem } \\
\text { foot placement), side-stepping to } \\
\text { the left }(1.5 \mathrm{~m}) \text { and repeating ten } \\
\text { times }\end{array}$ & \multirow{2}{*}{$\begin{array}{l}\text { Forward and backwards step-up } \\
\text { on and off of the foam, three } \\
\text { sets of ten each (eyes-open \& } \\
\text { eyes-closed) }\end{array}$} & $\begin{array}{l}\text { Step ups on high (10 inch) foam } \\
\text { step, three sets of ten (eyes- } \\
\text { open/closed) }\end{array}$ \\
\hline $\begin{array}{l}\text { Walking eyes-closed, forward } \\
(3 \mathrm{~m}) \text { and back }(3 \mathrm{~m}) \text { two sets of } \\
\text { five }\end{array}$ & & $\begin{array}{l}\text { Squats (eyes-open/hard surface; } \\
\text { eyes-closed/hard surface; eyes- } \\
\text { open/foam surface; eyes-closed } \\
\text { hard surface) ten repititions each }\end{array}$ \\
\hline $\begin{array}{l}\text { Walking eyes-closed, forward } \\
(3 \mathrm{~m}) \text { and backwards }(3 \mathrm{~m}) \text { over } \\
\text { obstacle two sets of five }\end{array}$ & $\begin{array}{l}\text { Isolated balancing on each leg } \\
\text { (front, side, and back leg kicks), } \\
\text { three sets of ten each (eyes- } \\
\text { open \& eyes-closed) }\end{array}$ & $\begin{array}{l}\text { Spinning in chair three times, } \\
\text { then getting up and walking } 6 \\
\text { steps on hard foam }\end{array}$ \\
\hline
\end{tabular}


the following: moving the hands away from one's sides/off of the iliac crests, opening one's eyes, stepping/stumbling, hip abduction or flexion beyond $30^{\circ}$ (e.g., crouching), remaining out of the proper testing position for over 5 seconds. Each error was given a point or 1 , and errors were counted throughout each trial. A higher score could be interpreted as lesser ability to balance; conversely, a lower score (i.e., fewer deviations) could be interpreted as a better ability to balance. Different than typical BESS assessments which simply compile the cumulative score for all the conditions collectively, in this study, errors were parsed out for each condition pre- and post- based on task-difficulty level.

\section{Center-of-pressure (COP) Forceplate Measures}

For standing balance, subjects were tested for eyes-open/eyes -closed (receiving/not receiving visual system input) for both wide/tandem foot placement conditions (wide foot placement and front-to-back foot placement, respectively) leading to four test conditions: 1) wide/eyes-open, 2) wide/eyesclosed, 3) tandem/eyes-open, 4) tandem/eyes-closed. For each condition, 4 sets of 20-second data were recorded, with a brief rest in between. During our experiments, subjects' standing balance medio-lateral ( $\mathrm{ML}$, or side-to-side) and anterior-posterior (AP, or front-to-back) COP position traces were measured using a Tekscan Forceplate Walkway and data acquisition involved the use of the Tekscan Forceplate Software, installed on a Dell PC computer within the lab. Each subjects' ground reaction force data was acquired at a rate of $50 \mathrm{~Hz}$. The Tekscan software allowed for the raw ground reaction force and COP position data to be exported. Shifts in COP position, or changes in the location (position) of resultant vertical ground reaction force vector, as a function of time were recorded. The measures extracted from the each of the ML and AP COP time-series were computed as shown in [15-22] and were: maximum displacement, root mean square displacement, mean velocity and root mean square velocity.

\section{Activities-specific Balance Confidence (ABC) Assessment} To assess participant balance confidence, the (standard) $A B C$ scale was used. The survey questions included (among others), "How confident are you that you will not lose your balance or become unsteady when you:Walk around the house? Walk up or down stairs? Bend over and pick up a slipper? Are bumped into by people as you walk?". From the total score, $100 \%=$ high level of physical function; $50-80 \%=$ moderate function; $<50 \%$ $=$ low function; and, in general, $<67 \%$ indicated risk for falling. In order to prevent bias in their responses, each participant was blind to their $A B C$ survey answers from their previous assessments.

\section{Data analysis}

Our BESS assessment \& ABC surveys were tabulated and analyzed in Excel (Microsoft Excel for Mac, Version 15.38, Microsoft Corporation). MATLAB software (MathWorks, R 2014a) was used for all post-processing of the forceplate COP data. The COP position trace as a function of time was post-processed to compute the above displacement and velocity, parameters from AP and ML COP position time series.

For pre- and post-results, average values for each above were computed. For the forceplate data there were 64 total trials for each of the four test conditions, pre-and post (256 trials total pre-and 256 trials total post). For the BESS data, there were 6 trials for each task-difficulty level per participant yielding 96 total trials/task-difficulty condition (i.e., hard surface/ double-leg, foam surface/double-leg, hard surface/tandem, foam surface/tandem, hard-surface/single-leg, foam surface/singleleg) for pre- and post, each. In terms of statistical analysis, SAS Software (SAS Institute Inc., Version 9.4) was used. For each group, for each test condition, trials were pooled from which means and standard errors were computed for the above parameters. For the BESS and ABC surveys, collective means and standard errors for the baseline and final assessments were determined. For the BESS assessments, results pre and post were pooled for each test condition. Differences were compared by using statistical analysis between the first and last assessments. Significant differences between pre and post were observed as $p$-values $<0.05$ and assessed using $t$-tests for equal sample size, unequal variance.

\section{Test-retest reliability}

The aim of this study was to use standard measures to assess the performance of the mature participants pre and post-training to test the hypothesis that modest and accessible training exercises targeting sensory inputs and BOS could improve balance in mature participants $(60-80$ years old). Although the purpose of this study was not to examine test-retest reliability of standardly used assessments (BESS, $C O P$, and $A B C$ ), it is briefly discussed here in terms of previous literature and what it means in terms of the interpretations of the results and their validity.

In terms of the BESS assessment itself, other commonly used functional balance tests (such as the Berg Balance Scale (BBS) and Timed Up and Go (TUG)), did not have the depth of information to discriminate between various sources of sensory information (i.e., visual, vestibular, or somatosensory) that BESS possessed. The BESS assessment is commonly used by both researchers and clinicians to evaluate balance. Part of its appeal is that it is easy to perform and requires little (no) equipment; physical therapists and clinicians may not have access to instrumented balance testing devices.

In terms of reliability of the BESS results, other studies have shown reliability is good. Reimann et al. [24] performed the first reliability study on Division I varsity athletes evaluated by 3 testers to determine intertester reliability; reliability was classified as good (intraclass correlations (ICC) were 0.78-0.96). Examples of other studies that have reported on the reliability of BESS are [25-32]. Valovich et al. [33] reported intrarater reliability from 0.87 to 0.98 . More recent examples 
are: Cushman et al. [34] and Carlson et al. [35]. Carlson et al. [35] investigated interrater and intrarater reliability to determine the minimum detectable BESS change in athletes with concussion. The interrater reliability was 0.75 and the intrarater reliability was 0.86 ; reliability values were moderate to good. In the currently presented study, only one rater recorded the BESS scores; with a previously reported intrarater reliability of 0.86 , this bolstered confidence that the results were reliable.

Further, in this study presented here BESS was not the sole source of assessment data; other measures aside from BESS ( $A B C$ and forceplate COP measures) were used such that a fuller perspective of changes in the participants' results pre-versus post could be evaluated. Force platforms (such as Tekscan) are commonly used in order to quantify balance and COP is a more sensitive and powerful way to detect differences in balance than perhaps BESS. The use of forceplates mitigates subjectivity and rater reliability issues associated with an observer-rated test (e.g., BESS). Countless studies (too many to list here) have used COP as a means to assess balance. The first study which used parameters extracted from COP (e.g., root mean square displacement, mean velocity, root mean square velocity and others) to form balance comparisons was Prieto et al. [15]. An example of a study that examined the test-retest reliability of COP was Pinsault and Vuillerme [36]. Results showed that intraclass correlation coefficients (ICCS) generally increased as the number of trials used to compute COP measures increased. It was observed that three $30 \mathrm{~s}$ trial recordings were sufficient to ensure excellent test-retest reliability of COP measures widely employed in clinical practice (e.g., sway area, range, mean and maximal velocities of the COP displacements). Here, within the current study, four, $20 \mathrm{~s}$ trial recordings were used to measure COP which was believed to unsure excellent test-retest reliability; this enhances confidence in our results. The $A B C$ scale is a popular, theoretically-based, reliable and valid tool designed to assess fear of falling and balance confidence. Unfortunately, there is limited data available on its test retest reliability.

\section{Results}

\section{BESS Assessment Performance}

For the BESS assessment, we compared the baseline and final results. We examined changes seen due to surface condition (foam and firm) "as well as" stance (double-leg, tandem, and singleleg); as previously mentioned, all BESS assessment trials were conducted with the eyes-closed.

Figure 1 shows the results pre-\& post training for BESS conditions of increasing difficulty level, left to right. For the double-leg stance, firm surface and double-leg stance, foam surface conditions, we did not see significant changes pre- versus post. This was due to the fact that participants were able to complete the task with no errors at pre (or baseline) prior to any training taking place. However, we observed significant changes (decreases in the numbers of errors) for the other conditions: tandem stance, hard (or firm) \& foam surfaces (firm/tandem: $d f=106$,

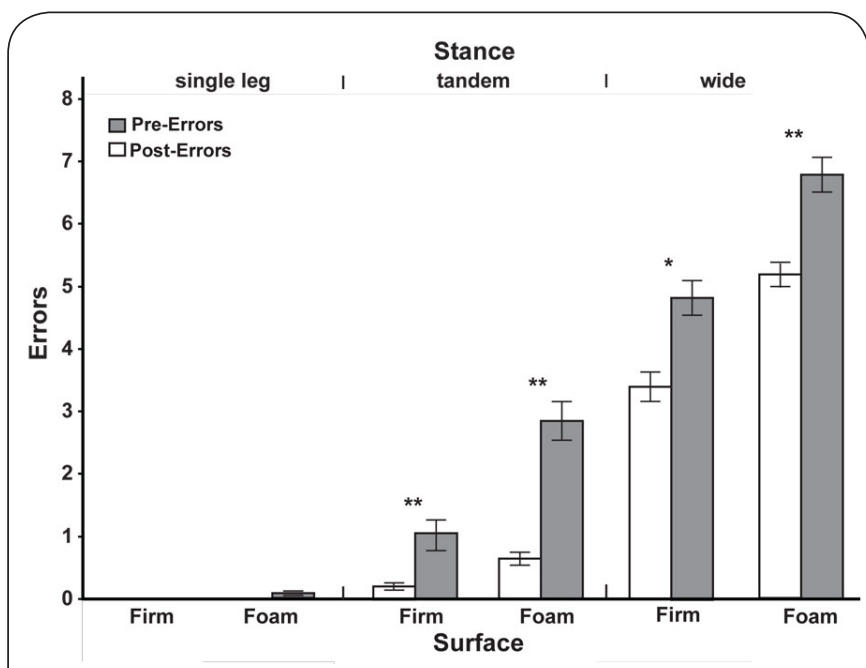

Figure 1. Mean BESS Errors at baseline (gray) and at final assessment (white) as a function of BESS test condition with standard error bars shown $(\mathrm{N}=16$, Trials/Condition $=96$ each, pre \& post).

$t=-3.34, p<0.0006$; foam/tandem: $d f=116, t=-6.76, p<0.0001$, respectively) and single-leg stance, firm \& foam surfaces (firm/ single-leg: $\mathrm{df}=180, \mathrm{t}=-3.96, \mathrm{p}<0.0001$; foam/single-leg: $\mathrm{df}=64$, $\mathrm{t}=-4.74, \mathrm{p}<0.0001$, respectively). Further, the total/composite BESS score significantly decreased from a mean of $15.5 \mathrm{er}-$ rors at baseline to 9.5 errors as shown in Table 2. Previously, Iverson and Koele [37] developed BESS normative reference data for adults and older adults which are also shown.

\section{ABC Performance}

For the $A B C$ surveys, in order to not skew their answers, as previously stated participants were blind to their previous survey results. A $100 \%$ response would mean that the individual was completely confident in terms of their balance, while $0 \%$ would mean the opposite (no balance confidence). For the assessments, $A B C$ results reflected balance confidence of $88 \%+/-14 \%$ at baseline and $90.4+/-10.5 \%$ at the conclusion respectively; there was no significant difference. In general, balance confidence was relatively high in that the participants

Table 2. BESS Performance: Previous Results (left) \& Current Results Pre and Post (right).

\begin{tabular}{|c|c|c|c|c|}
\hline \multirow[t]{2}{*}{$\begin{array}{c}\text { BESS } \\
\text { Performance }\end{array}$} & \multirow{2}{*}{$\begin{array}{c}\text { Total BESS } \\
\text { Errors } \\
\text { Males \& } \\
\text { Females (60-64 } \\
\text { yrs old) }\end{array}$} & \multirow{2}{*}{$\begin{array}{c}\text { Total BESS } \\
\text { Errors } \\
\text { Males \& } \\
\text { Females (65- } \\
69 \text { yrs old) }\end{array}$} & \multicolumn{2}{|c|}{$\begin{array}{c}\text { Total BESS Errors } \\
\text { Males }(64.7+/-3.5 \text { yrs old }) \& \\
\text { Females }(69.8+/-6.3 \text { yrs old })\end{array}$} \\
\hline & & & Pre & Post \\
\hline superior & $0-8$ & $0-12$ & & $9.5+/-1.7$ \\
\hline above average & $9-12$ & $13-15$ & & \\
\hline average & $18+/-7.8$ & $19.9+/-7.1$ & $15.5+/-2.0$ & \\
\hline broadly normal & $13-22$ & $16-24$ & & \\
\hline below average & $29-40$ & $25-32$ & & \\
\hline poor & $29-40$ & $33-38$ & & \\
\hline \multicolumn{3}{|c|}{ Iverson and Koele 2013} & \multicolumn{2}{|c|}{ Current Study } \\
\hline
\end{tabular}


were healthy individuals.

\section{COP changes}

The participants were assessed using the forceplate walkway for both quiet standing and gait. Figure 2 displays the AP and ML COP parameter quiet standing results for baseline (or pre) and final (or post) for quiet standing conditions: eyes-open /wide stance (EO wide), eyes-closed/wide stance (EC wide), eyes-open/tandem stance (EO tandem), eyes-closed/tandem stance (EO tandem). There were significant decreases (improvements) in balance and control of balance observed between pre- and post. For ML root mean square displacement, there were significant decreases for EO tandem \& EC tandem $(p<0.001)$. For ML maximum displacement, there were significant decreases observed for all conditions (EO wide, EO tandem and EC tandem $(p<0.001)$ and $E C$ wide $(p<0.002))$. For both $M L$ mean velocity and $M L$ root mean square velocity, there were significant decreases pre- versus post $(p<0.001)$ for all conditions. Furthermore, for all AP parameters (i.e., both displacement and velocity), for all conditions decreases were significant $(p<0.001)$ between post compared to pre.

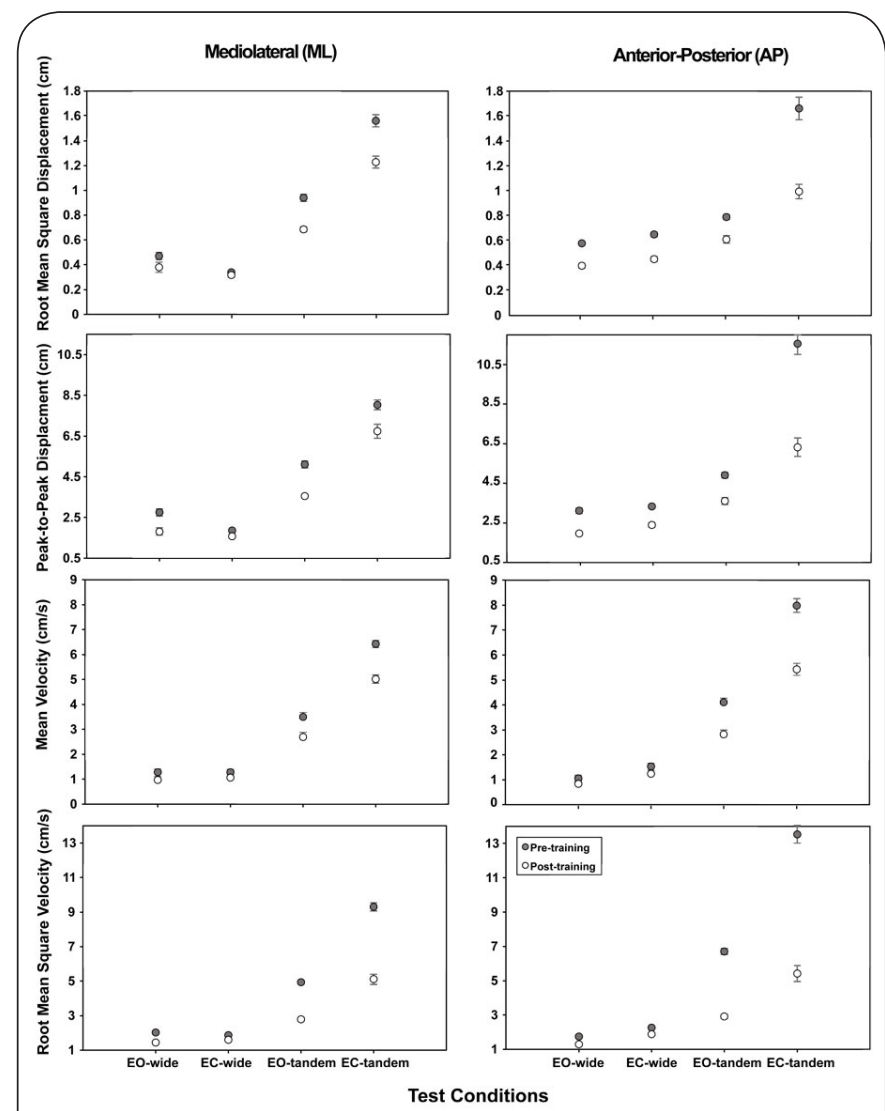

Figure 2. Mean ML (left) and AP (right) COP displacement and velocity parameters at baseline (gray) and at final assessment (white) as a function of forceplate test condition with standard error bars shown $(\mathrm{N}=16$, Trials/Condition=64).

\section{Discussion}

The purpose of this study was to determine if modest and accessible training exercises targeting sensory inputs and BOS could improve balance and balance confidence in healthy, mature participants (60-80 years old). Balance improvements were observed in the participants via decreases in BESS scores and decreases in AP \& ML COP measures post- training. Balance confidence, measured using the $A B C$ survey, did not increase post-training.

\section{BESS changes}

Over the course of several sessions, participants' BESS scores improved from the broadly normal range at baseline to the superior performance range at the conclusion of the training (as shown in Table 2). Using the BESS ranges established by Iverson and Koele [37], pooled results for all participants showed that at baseline (mean +/- standard deviation $=15.5$ $+/-2.0$ errors) which was moved to the superior performance range (mean $+/$ - standard deviation $=9.5+/-1.7$ errors) at the final assessment. Of note, are the decreases in scores for the single-legged stance conditions (Figure 1); this is particularly important in that for gait there is increased time spent in single-leg stance phase when the swing (opposing) limb is, for example, going over an obstacle. This result was interpreted to mean that through our targeted foam and isolated leg exercises (with eyes closed) trained the individuals to re-weight other cues (perhaps vestibular) when vision and somatosensory (support surface cues) are limited or unreliable. This is of particular relevance and utility in the real-life scenario of one getting out of bed at night, and walking on soft carpet; such cases lead to high risks of falls.

\section{AP \& ML COP changes}

Improvements (decreases) in both AP \& MLCOP displacement and velocity were observed. This finding was interpreted as the participants' increased ability to control their posture in both planes. In previous studies [15-22], the COP velocity and displacement parameters have been sensitive towards distinguishing between various populations; balance performance could be characterized via COP displacement and velocity response curves. From the COP position time series, displacement and velocity parameters were computed and plotted as a function of increasing test condition difficulty level. COP parameters showed decreases with increased test difficulty in the final assessment compared to the baseline assessment; this demonstrated participants' better ability to control their balance at the conclusion of the training.

Imbalance and tripping over obstacles during walking are common causes of falls in the elderly. Inappropriate body segment coordination, in response to the obstacle, perturbs balance in the frontal plane and causes falls to the side in elderly; this fall may cause hip or pelvis fracture [38]. Improved ML movements, such as we observed here, can be used as a potential indicator of increased balance maintenance in 
individuals and their greater risk of a fall. Consistent with our observations, Chou et al. [39] conducted a study to investigate whether elderly patientswith imbalance can be distinguished from healthy elderly subjects their COM motion in the ML direction during obstacle crossing.

The ML improvements (seen as decreases in COP displacement and velocity parameters) were particularly encouraging. Fall-prone elderly tend to have ML excursions of the body COM and more irregular lateral foot placements [26], and an impaired ability to control ML stability may distinguish elderly "fallers" from "nonfallers." Aging has been observed to bring about issues particularly involved with controlling lateral stability during the execution of the step, and further, older adults have difficulty in controlling lateral stability when stepping to recover balance [39]. Improving ML stability with training could lead to decreases in fall-risk. Improvements (decreases) in ML COP parameters were interpreted as an increase in lateral balance control, hence, decrease in fall-risk.

\section{ABC Performance}

The $A B C$ survey data showed only moderate, but insignificant, improvements in balance confidence. This stems from the fact that the mature persons investigated were generally healthy individuals. Collectively, their perceived ability to balance did not change, however, their balance ability did in fact improve (as reflected by the BESS \& COP results).

\section{Conclusion}

Participant training over several weeks led to targeted single-leg stability, ML (and AP) stability awareness and maintenance. Our results assist in determining accessible exercises which seniors could do while at home (i.e., outside of a clinical setting) to help them improve their balance could involve, for example, training which utilizes eyes-open/closed and balancing activities on compliant surfaces, such as foam. A goal of future work is to include a larger number of older participants from a broader demographic. Such training exercises could potentially be used on impaired populations, such as older individuals whom had suffered a stroke.

\section{Competing interests}

The author declares that he has no competing interests.

\section{Acknowledgements and Funding}

Dr. Thompson would like to acknowledge her current funding support from the National Science Foundation (NSF): Award Abstracts 1533479, 1654474, and 1700219.

\section{Publication history}

Editor: Gordon John Alderink, Grand Valley State University, USA. Received: 06-Aug-2019 Final Revised: 13-Sept-2019

Accepted: 06-Oct-2019 Published: 22-Oct-2019

\section{References}

1. Falls Prevention Facts. National Council on Aging (NCOA). 2017. Website

2. Important Facts about Falls. Centers for Disease Control (CDC) and Prevention. 2017| Website

3. NIA Strategic Directions. Aging Well in the $21^{\text {st }}$ Century: Strategic Directions for Research on Aging. 2016. I Website

4. Burns ER, Stevens JA and Lee R. The direct costs of fatal and non-fatal falls among older adults - United States. J. Safety Res. 2016; 58:99-103. | Article

5. Wiesmeier IK, Dalin D, Wehrle A, Granacher U, Muehlbauer T, Dietterle J, Weiller C, Gollhofer A and Maurer C. Balance Training Enhances Vestibular Function and Reduces Overactive Proprioceptive Feedback in Elderly. Front Aging Neurosci. 2017; 9:273. | Article | PubMed Abstract | PubMed FullText

6. Rendon AA, Lohman EB, Thorpe D, Johnson EG, Medina E and Bradley B. The effect of virtual reality gaming on dynamic balance in older adults. Age Ageing. 2012; 41:549-52. | Article I PubMed

7. Nagy E, Feher-Kiss A, Barnai M, Domjan-Preszner A, Angyan L and Horvath G. Postural control in elderly subjects participating in balance training. Eur J App/ Physiol. 2007; 100:97-104. I Article I PubMed

8. Gillespie LD, Robertson MC, Gillespie WJ, Sherrington C, Gates S, Clemson $\mathrm{LM}$ and Lamb SE. Interventions for preventing falls in older people living in the community. Cochrane Database Syst Rev. 2012; CD007146. | Article I PubMed

9. Weerdesteyn V, Nienhuis B and Duysens J. Exercise training can improve spatial characteristics of time-critical obstacle avoidance in elderly people. Hum Mov Sci. 2008; 27:738-48. I Article I PubMed

10. Horak FB and Macpherson JM. Postural orientation and equilibrium. Comprehensive Physiology. 1996. I Article

11. Rauch SD, Velázquez-Villase-or L, Dimitri PS and Merchant SN. Decreasing hair cell counts in agin humans. Ann. N.Y. Acad. Sci. 2001; 942:220-22. I Article

12. Goble DJ, Coxon JP, Wenderoth N, Van Impe A and Swinnen SP. Proprioceptive sensibility in the elderly: degeneration, functional consequences and plastic-adaptive processes. Neurosci Biobehav Rev. 2009; 33:271-8. | Article | PubMed

13. Grossniklaus HE, Nickerson JM, Edelhauser HF, Bergman LA and Berglin L. Anatomic alterations in aging and age-related diseases of the eye. Invest Ophthalmol Vis Sci. 2013; 54:ORSF23-7. | Article | PubMed Abstract | PubMed FullText

14. Shumway-Cook A and Woollacott M. Chapter 9: Aging and postural control, in Motor Control: Theory and Practical Applications, 2nd Edn ed M. Biblis (Philadelphia, PA: Lippincott Williams \& Wilkins). 2001; 222-247.

15. Prieto TE, Myklebust JB, Hoffmann RG, Lovett EG and Myklebust BM. Measures of postural steadiness: differences between healthy young and elderly adults. IEEE Trans Biomed Eng. 1996; 43:956-66. | Article | PubMed

16. Thompson LA, Haburcakova C and Lewis R. Postural compensation strategy depends on th severity of vestibular damage. Heliyon. 2017; 3:e00270. | Article

17. Thompson LA, Badache M, Brusamolin JAR, Guise J, Behera L, Estrada SC, Savadkoohi M, Guerrero PS and Shetty D. Exploring Assistive Technologies towards the Improvement of Elderly Balance and Balance Confidence. (IMECE 2018-86815), IMECE. 2018; V003T04A038. I Article

18. Thompson LA, Badache $M$, Cale S, Behera $L$ and Zhang N. Balance Performance as Observed by Center-of-Pressure Parameter Characteristics in Male Soccer Athletes and Non-Athletes. Sports (Basel). 2017; 5. | Article | PubMed Abstract | PubMed FullText

19. Badache $M$, Behera $L$, Zhang $N$ and Thompson LA. Investigating female athletes' balance using center-of-pressure (COP) derived displacement and velocity parameters. Technical paper publication (IMECE201770730), ASME IMECE 2017. | Article

20. Thompson LA, Haburcakova $C$ and Lewis RF. Vestibular ablation and a 
semicircular canal prosthesis affect postural stability during head turns. Exp Brain Res. 2016; 234:3245-3257. | Article | PubMed Abstract | PubMed FullText

21. Thompson LA and Badache M. Investigating Center-of-Pressure Parameters to Quantify Athlete and Non-Athlete Balance. Technical Paper Publication (IMECE 2016-65642), ASME IMECE 2016. | Article

22. Carpenter MG, Adkin AL, Brawley LR and Frank JS. Postural, physiological and psychological reactions to challenging balance: does age make a difference? Age Ageing. 2006; 35:298-303. | Article | PubMed

23. Maki BE and Mcllroy WE. The role of limb movements in maintaining upright stance: the "change-in-support" strategy. Phys Ther. 1997; 77:488-507. | Article | PubMed

24. Reimann BL, Guskiewicz KM and Shields EW. Relationship between clinical and forceplate measures of postural stability. J Sport Rehab. 1999; 8:71-82.

25. Broglio SP, Zhu W and Sopiarz K et al. Generalizability theory analysis of Balance Error Scoring System rehabilitee in healthy young adults. J Athl Train. 2009; 44:497-502.

26. Erkman $\mathrm{N}$ Taskin $\mathrm{H}$ Kaplan $\mathrm{T}$ et al. The effect of fatiguing exercise on balance performance as measured by the Balance Error Scoring System. Isokinet Exerc Sci. 2009; 17:121-127.

27. Finnoff JT, Peterson VJ, Hollman JH and Smith J. Intrarater and interrater reliability of the Balance Error Scoring System (BESS). PM R. 2009; 1:504. | Article | PubMed

28. Hunt TN, Ferrara MS, Bornstein RA and Baumgartner TA. The reliability of the modified Balance Error Scoring System. Clin J Sport Med. 2009; 19:471-5. | Article | PubMed

29. McLeod TC, Armstrong T, Miller M and Sauers JL. Balance improvements in female high school basketball players after a 6-week neuromusculartraining program. J Sport Rehabil. 2009; 18:465-81. | PubMed

30. Susco TM, Valovich McLeod TC, Gansneder BM and Shultz SJ. Balance Recovers Within 20 Minutes After Exertion as Measured by the Balance Error Scoring System. J Athl Train. 2004; 39:241-246. | PubMed Abstract | PubMed FullText

31. Valovich McLeod TC, Barr WB, McCrea M and Guskiewicz KM. Psychometric and measurement properties of concussion assessment tools in youth sports. J Ath/ Train. 2006; 41:399-408. | PubMed Abstract I PubMed FullText

32. Valovich McLeod TC. The value of various assessment techniques in detecting the effects of concussion on cognition, symptoms, and postural control. J Athl Train. 2009; 44:663-5. | Article | PubMed Abstract | PubMed FullText

33. Cushman D, Hendrick J, Teramoto M, Fogg B, Bradley S and Hansen C. Reliability of the balance error scoring system in a population with protracted recovery from mild traumatic brain injury. Brain Inj. 2018; 32:569-574. | Article | PubMed

34. Carlson CD, Langdon JL, Munkasy BA, Evans KM and Buckley TA. Minimal Detectable Change Scores and Reliability of the Balance Error Scoring System in Student-Athletes With Acute Concussion. Athletic Training and Sports Health Care. 2019.

35. Bell DR, Guskiewicz KM, Clark MA and Padua DA. Systematic review of the balance error scoring system. Sports Health. 2011; 3:287-95. I Article | PubMed Abstract | PubMed FullText

36. Pinsault $N$ and Vuillerme $N$. Test-retest reliability of centre of foot pressure measures to assess postural control during unperturbed stance. Med Eng Phys. 2009; 31:276-86. | Article | PubMed

37. Iverson GL and Koehle MS. Normative data for the modified balance error scoring system in adults. Brain Inj. 2013; 27:596-9. | Article | PubMed

38. Horak FB. Postural orientation and equilibrium: what do we need to know about neural control of balance to prevent falls? Age Ageing. 2006; 35 Suppl 2:ii7-ii11. | Article | PubMed

39. Chou LS, Kaufman KR, Hahn ME and Brey RH. Medio-lateral motion of the center of mass during obstacle crossing distinguishes elderly individuals with imbalance. Gait Posture. 2003; 18:125-33. | Article | PubMed

\section{Citation:}

Thompson LA. Moderate sensory balance training leads to improvements in elderly. Phys Ther Rehabil. 2019; 6:12. http://dx.doi.org/10.7243/2055-2386-6-12 